\title{
32. On the Experience of the Brachial Vertebral Angiography
}

\author{
Teruyoshi Hashiba, Yuji Miyazaki, Hiroshi Kimura, \\ Tsutomu TOGaSHI AND Toyoaki CHIBA \\ Department of Neurosurgery, Sapporo Medical College and Hospital
}

As vertebral angiography has great value in diagnosing lesions in the posterior fossa, various techniques have been described by many authors:

(1) Direct puncture of the vertebral artery.

a) percutaneous method: Berczeller \& Kugler, Takahashi, Sugar et al. Sjögren.

(2) Indirect method; retrograde injection of contrast media via the subclavian, common carotid or right brachial artery.

a) percutaneous method: Shimidzu.

b) open method: Moniz, Krayenbühl, Gould, Schaerer, Hashiba.

(3) Catheter method: Radner, Olsson.

The open indirect method, described by Schaerer, has been used in our clinic, but it's procedure needs skill, especially in cases of children.

We have carried out brachial vertebral angiography, described by Gould et al., on 9 adults and 16 children and identified it as an easy, reliable and safe method.

\section{Method}

(1) Exposure of right brachial artery

Under local anesthesia a skin incision, $3-4 \mathrm{~cm}$. long, is made over the bicipital groove at the junction of the middle and distal thirds of the arm. The brachial fascia is incised and a $3 \mathrm{~cm}$. segment of the artery is mobilized and isolated by placing behind it a small vinyl tube.

(2) Injection of contrast media and X-ray photograph.

Intravenous anesthesia with thiopentothal-sodium is used to avoid angiospasm. Two bulldog clamps are placed on the proximal and distal sides of expected cannulated area. After the insertion of the needle in the artery, the proximal clamp is removed and contrast media is injected as rapidly as possible. The usual amount of contrast media ( $60 \%$ Urografin) is $20 \mathrm{cc}$. in children and $30-40$ cc. in adults.

Three radiographic exposures in lateral projection and two anteroposterior are made. The first exposure $(2-3 \mathrm{sec}$.) is made just before the injection of dye is completed: next exposure $(0.5 \mathrm{sec}$.), at $1.0 \mathrm{sec}$. intervals thereafter.

Bleeding from vessel wall was controlled easily with gauze tampon. 